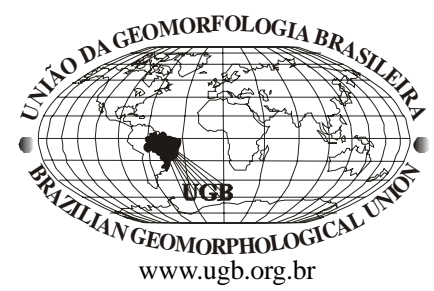

\title{
EVOLUÇÃO HISTÓRICO-GEOGRÁFICADA OCUPAÇÃO DESORDENADA E MOVIMENTOS DE MASSA NO MUNICÍPIO DE PETRÓPOLIS, NAS ÚLTIMAS DÉCADAS
}

\author{
Antonio José Teixeira Guerra \\ PhD em Erosão dos Solos, professor associado do Departamento de Geografia - UFRJ \\ antoniotguerra@gmail.com \\ Luiz Fernando Hansen Gonçalves \\ Mestre em Geografia pela UFRJ, professor do Colégio Pedro II, Rio de Janeiro \\ lfhg@compuland.com.br
}

Patrícia Batista Melo Lopes

Mestre em Geologia pela UERJ e pesquisadora associada do Lagesolos patricialopesufrj@yahoo.com.br

\begin{abstract}
Resumo
Esse artigo aborda a ocorrência de movimentos de massa no município de Petrópolis, levando em conta o seu crescimento urbano, em conjunto com as características físicas. Alem disso, foi também pesquisado como a escala temporal, com o objetivo de compreender como a urbanização desorganizada tem causado diferentes tipos de movimentos de massa, que tem levado a mortes, bem como diferentes tipos de prejuízos, na cidade de Petrópolis. Ao mesmo tempo, esses tipos de degradação de terras causam prejuízos e tornam as encostas com maiores riscos para a ocupação humana.
\end{abstract}

Palavras-chave: movimentos de massa; degradação de terras; ocupação humana

\begin{abstract}
:
This paper regards the occurrence of mass movements in Petropolis municipality, taking into account its urban growth, together with physical characteristics. Furthermore, we look into its temporal scale, in order to assess how the disorganized urbanization has been causing so many types of mass movements, leading to human deaths and also different kinds of damages within Petropolis city. At the same time, these types of land degradation cause urban damages and make some of the slopes very risky to human settlement.
\end{abstract}

Keywords: mass movements; land degradation; human settlement

\section{Introdução}

Este artigo aborda a ocorrência de movimentos de massa em Petrópolis, através do reconhecimento do meio físico, onde a área urbana se estabelece e expande, de forma a considerar as suas limitações à ocupação humana. Além disso, procura avaliar dentro de uma escala temporal, como a desordenada ocupação humana pode ser capaz de potencializar as limitações naturais, restringindo a ocupação e aumentando a ocorrência de movimentos de massa, que tornaram o município nacionalmente conhecido.

O município de Petrópolis localiza-se a norte da cidade do Rio de Janeiro (Figura 1), entre as coordenadas geográficas 


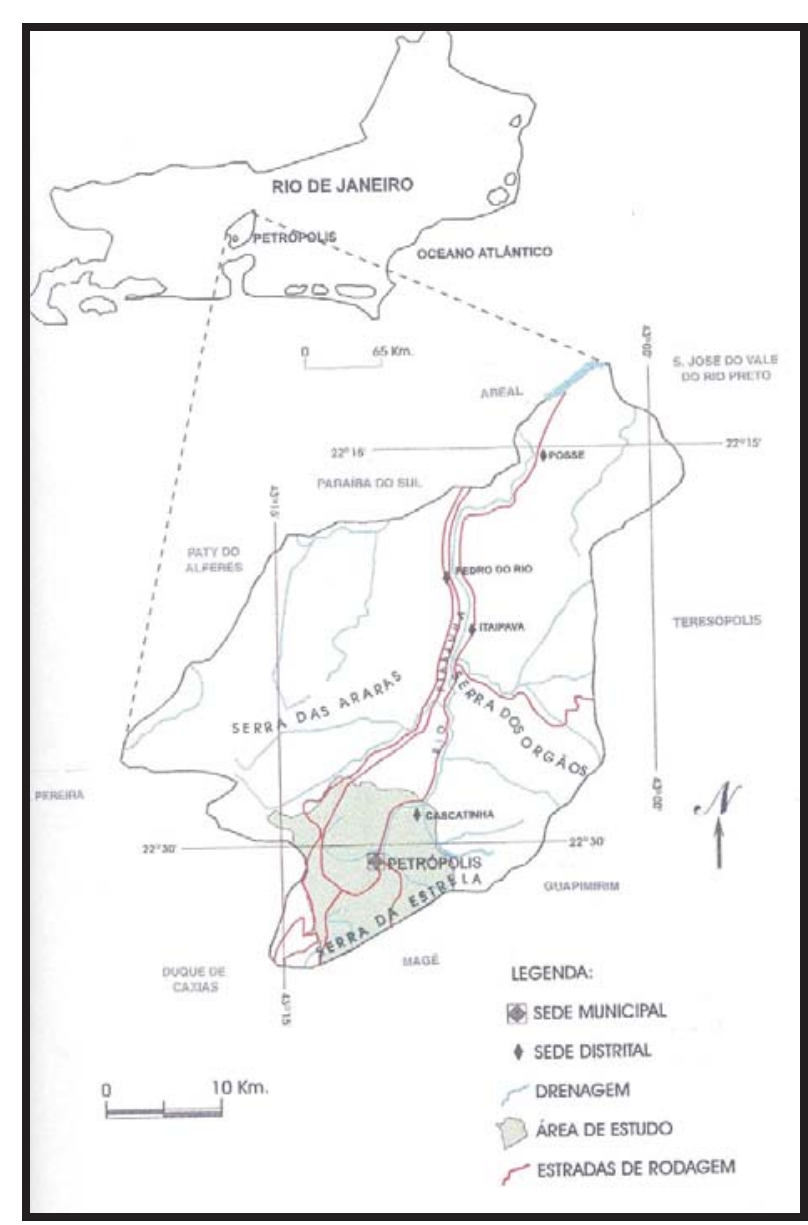

Figura 1 - Mapa de localização do município de Petrópolis.

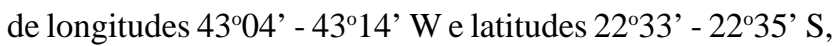
com altitude média de 845 metros, abrangendo uma área de $811 \mathrm{~km}^{2}$. Segundo dados do IBGE (2004), sua população é de aproximadamente 300.000 habitantes, dos quais 97,5\% estão situados na área urbana do município.

A cidade de Petrópolis está situada aproximadamente 60 quilômetros ao norte da cidade do Rio de Janeiro, sobre a Serra do Mar e Serra dos Órgãos, com suas encostas variando, na grande maioria entre $5^{\circ}$ e $60^{\circ}$ de declividade. O município ocupa uma área serrana, estruturada sobre rochas bastante falhadas e fraturadas, encostas íngremes e, em alguns pontos, solos com perfis bastante profundos, possuindo partes do município com totais pluviométricos anuais acima de 2.000 $\mathrm{mm}$, com chuvas concentradas nos meses que vão de novembro a março (Guerra e Favis-Mortlock, 1998; Gonçalves e Guerra, 2006; Guerra et al, 2007).

A urbanização que vem se processando no município, desde a sua criação em 1843, aliada às condições geológicas, geomorfológicas, climatológicas e pedológicas, têm sido as responsáveis pela degradação ambiental, que tem se verificado, em especial, nas últimas quatro décadas (Almeida et al, 1991; Guerra, 1995; Gonçalves, 1998; Guerra et al, 2007).
Em função disso, esse artigo aborda os problemas relacionados à degradação ambiental, tendo como principal objetivo compreender as causas e conseqüências dos movimentos de massa, que tanto têm afligido a população do município. Para isso, será analisado como a urbanização desordenada tem influenciado na ocorrência de movimentos de massa, através de um histórico de seu planejamento urbano, do crescimento populacional e da legislação do espaço urbano, bem como da ocupação do solo e sua relação com a incidência dos movimentos de massa. Uma caracterização de seu quadro físico é também necessária e, portanto, o clima, a cobertura vegetal, a geologia e o relevo são, para tal, analisados.

A escolha da área de estudo, $1^{\circ}$ distrito (Petrópolis) e parte do $2^{\circ}$ distrito (Cascatinha) deve-se ao fato de ser a porção mais urbanizada dentre os cinco distritos de Petrópolis $\left(3^{\circ}\right.$ distrito - Itaipava, $4^{\circ}$ distrito - Pedro do Rio e $5^{\circ}$ distrito Posse), dispostos no sentido sul-norte, seguindo o curso do principal rio do município - o Piabanha - um dos afluentes do rio Paraíba do Sul (Figura 1).

Esta área é a mais afetada pelos movimentos de massa, especialmente por escorregamentos. Concentra a maior parte da população do município, ao longo das estreitas planícies aluviais e encostas, sendo um exemplo de cidade onde o equilíbrio com a natureza foi rompido, o que pode ser observado pela incidência de movimentos de massa (Gonçalves, 1998).

\section{Caracterização física da área estudada}

Petrópolis possui os seguintes limites: Teresópolis, Guapimirim, Magé, Duque de Caxias, Miguel Pereira, Paty do Alferes, Paraíba do Sul, Areal e São José do Vale do Rio Preto, delimitando uma área de $83,11 \mathrm{~km}^{2}$ ou 8.311 hectares, que no município de Petrópolis abrange a escarpa da Serra do Mar, que constitui a transição entre a Baixada Fluminense e o Planalto, inserindo-se neste último a maior parte do município. Localmente, a Serra do Mar recebe as denominações de Serra dos Órgãos e Serra da Estrela. Predominam no embasamento, rochas do Complexo Cristalino, com granitos, gnaisses e migmatitos.

É uma das poucas cidades, que dentro do Estado do Rio de Janeiro ainda conserva e integra-se a parques nacionais e reservas biológicas - Parque Nacional da Serra dos Órgãos, Reserva Biológica de Araras, Reserva Biológica do Tinguá, Reserva Ecológica da Alcobaça, Zona de Vida Silvestre da Maria Comprida, Zona de Vida Silvestre de Araras e Unidade de Conservação "Parque da Serra da Estrela” - além de possuírem dentro de seu sítio urbano, áreas de Mata Atlântica, tombadas pela União - a APA (Área de Proteção Ambiental) de Petrópolis (Gonçalves, 1998). 


\section{Clima}

O município de Petrópolis localiza-se de forma abrangente no domínio tropical, onde a posição geográfica, a altitude, o relevo movimentado, a influência da maritimidade, juntamente com a circulação atmosférica, estabelecem variações climáticas expressivas, ocasionando diferenciações nos índices térmicos e pluviométricos ao longo do ano (Nimer, 1989).

Localmente, o relevo atua como fator importante no aumento da turbulência do ar (ascendência orográfica), principalmente nas passagens de frentes frias e linhas de instabilidade, onde o ar se eleva e perde temperatura, ocasionando fortes e prolongadas chuvas. Sendo assim, são abundantes as chuvas de concentração/hora, com destaque na vertente meridional da Serra dos Órgãos, onde está localizado o município.

Quanto ao tipo de clima, segundo a classificação climática proposta por Nimer (1989), a área de estudo apresenta o clima mesotérmico brando superúmido. A precipitação média anual é de $2200 \mathrm{~mm}$, com temperaturas inferiores a $18^{\circ} \mathrm{C}$ no inverno (julho) e de $21^{\circ} \mathrm{C}$ no verão (fevereiro) e a umidade atmosférica varia em torno de 83\% ao longo do ano. Nos trechos elevados da Serra dos Órgãos verifica-se maior freqüência dos ventos de sentido Sudoeste/ Nordeste, influenciados também pela orientação do relevo Sudoeste/Nordeste (FIDERJ - Fundação Instituto Brasileiro de Desenvolvimento Econômico e Social do Rio de Janeiro, 1978).

As chuvas se concentram de outubro a março, ocorrendo com maior intensidade no mês de dezembro, quando os índices pluviométricos chegam a 316 mm (15\% das chuvas anuais). No período menos chuvoso, que vai de maio a agosto, o mês de julho apresenta o menor índice pluviométrico com $66 \mathrm{~mm}$, correspondendo a 3\% das chuvas anuais. Embora os índices de umidade sejam elevados no município, o regime pluviométrico acompanha o ritmo característico do interior, isto é, as precipitações se reduzem no inverno (Nimer, 1989; Gonçalves, 1998).

\section{Cobertura vegetal}

O Projeto RADAM (Brasil, 1983), subdividiu a Mata Atlântica em diversos tipos florestais, que receberam a denominação de Floresta Ombrófila Densa.

A designação Floresta Ombrófila Densa, foi proposta por Ellenberg e Mueller-Dombois (1966), sendo que o termo Ombrófila (de origem grega), substitui Pluvial (de origem latina), ambas com o mesmo significado. Posteriormente, serviu de base para uma classificação apresentada à UNESCO (1973), sendo a partir de então bastante adotada.

Este tipo de vegetação caracteriza-se pela presença de fanerófitas perenifoliadas, com brotos foliares sem proteção contra a seca. Os ambientes ocupados pela Floresta Ombrófila Densa, apresentam chuvas bem distribuídas, com médias anuais em torno e acima de $1500 \mathrm{~mm}$, havendo estações sem seca, ou mesmo com grande disponibilidade de umidade.

A subdivisão da Floresta Ombrófila Densa (Mata Atlântica), realizada pelo RADAM (Brasil, 1983), baseou-se principalmente na distribuição por altitude, sendo reconhecidas na área de estudo em Petrópolis: Floresta Submontana, Floresta Montana, Floresta Alto Montana e Vegetação Secundária.

\section{Geologia}

A litologia da área de estudo é constituída predominantemente por rochas pertencentes ao complexo granítico-gnáissico-migmatítico de idade Pré-Cambriana. Estas rochas encontram-se intensamente seccionadas por fraturas e falhas de extensão regional, com forte reflexo na topografia, pois toda região de abrangência destas unidades foi submetida a eventos tectônicos caracterizados durante o período Pré-Cambriano (DRM, 1981; Penha et al, 1981). Geologicamente, observa-se a seguinte distribuição:

- Unidade de migmatitos heterogêneos: presente na porção noroeste e sudeste, constituindo a Unidade Santo Aleixo.

- Unidade de granitos gnáissicos: ocorre na porção central e sudeste e constitui a Unidade Batólito Serra dos Órgãos.

· Unidade de migmatitos homogêneos: na porção central e sudoeste, correspondendo a Unidade Bingen.

- Unidade de granitos intrusivos: em corpos menores na porção leste, correspondente ao Granito Andorinha.

Dentre as quatro unidades litológicas, a Unidade Bingen é predominante, correspondendo a 61,58\% da área, seguindo-se pela Unidade Santo Aleixo, com 21,2\%, Unidade Batólito Serra dos Órgãos, com 13,3\% e Unidade Granito Andorinha, com 0,9\% da área delimitada.

As características gerais do relevo são determinadas pelo controle estrutural, padrão de fraturamento e posição em relação à escarpa principal (limite meridional do domínio serrano). As estruturas regionais desempenham um notável controle na organização da rede de drenagem e no modelado do relevo. Os sistemas de fraturas e falhas mais importantes têm direção $\mathrm{N} 35^{\circ} \mathrm{E}$.

\section{Geomorfologia}

A área de estudo se insere na Região das Escarpas e Reversos da Serra do Mar, inserida em uma das quatro unidades que compõem esta região, a Unidade Geomorfológica da Serra dos Órgãos (Brasil, 1983) 
Esta região apresenta um quadro morfológico relacionado aos efeitos de um tectonismo regional e de sucessivas fases erosionais. Trata-se de uma área resultante de dobramentos, reativações de falhas e remobilização de blocos. A topografia reflete esses condicionamentos geológicos predominantes, e em toda a sua extensão são registrados vales alongados, segmentos de drenagem retilíneos, maciços graníticos, linhas de cristas e cumeadas paralelas, relevos com grandes desníveis altimétricos, escarpas íngremes e alvéolos intermontanos.

Os estudos sobre os deslizamentos de terra não são significativos apenas para as cidades situadas no planalto cristalino e zonas litorâneas, como os casos de Petrópolis, Teresópolis, Caraguatatuba e Rio de Janeiro, mas também para todas as áreas urbanizadas que englobam diversos tipos de encostas. O desenvolvimento dos estudos e mapeamentos geotécnicos vem oferecendo informações e documentos valiosos para a compreensão da dinâmica geomorfológica em áreas urbanizadas (Christofoletti, 1994).

A avaliação do mapa geomorfológico demonstra um predomínio de duas feições na área, como as rampas que ocupam $41,35 \%$ e o embasamento cristalino com $41,8 \%$. Os terraços fluviais representam $9,3 \%$, localizando-se ao longo dos rios expandindo-se quando o relevo permite. Os afloramentos correspondem a 6,3\%, ocorrendo sempre em áreas de maior altitude, nos topos das elevações ou sob a forma de rampas.

Quanto à declividade em Petrópolis, obtivemos as seguintes porcentagens para a área: 3-8\% (3,84\%), 8-20\% (9,72\%), 20-45\% (22,9\%), 45-75\% (35,7\%) e superiores a 75\% (26,53\%). Na avaliação dos resultados da carta de declividade, percebe-se um predomínio do relevo montanhoso e escarpado para onde a área urbana se expande através da abertura de loteamentos irregulares e invasões.

\section{Urbanização e ocorrência de movimentos de massa em Petrópolis}

A ampliação de áreas urbanizadas, devido à construção de áreas impermeabilizadas, repercute na capacidade de infiltração das águas no solo, favorecendo o escoamento superficial e a concentração das enxurradas. A urbanização afeta o funcionamento do ciclo hidrológico, pois interfere no rearranjo do armazenamento e na trajetória das águas. O homem ao introduzir novas maneiras para a transferência das águas, na área urbanizada e em torno das cidades, provoca alterações na estocagem hídrica nas áreas circunvizinhas e ocasiona possíveis efeitos adversos e imprevistos, no tocante ao uso do solo (Christofoletti, 1994).

Apesar dos fenômenos de chuvas de forte intensidade e escorregamentos serem mais propensos nas regiões tropicais, o aumento da ocupação de áreas pelas atividades antrópicas, desencadeia reações, que associadas ao mau uso, manejo e conservação dos solos, vêm gerando problemas ambientais, principalmente em áreas de topografia acidentada, como ocorre no município de Petrópolis, que ainda são agravados pelo desmatamento e ocupação desordenada das encostas. O desencadeamento de escorregamentos em uma dada região depende de vários condicionantes naturais, porém a chuva é um dos fatores mais significativos, pois quase todos os registros estão associados a episódios de chuvas de forte intensidade, ou de períodos prolongados, geralmente concentrados em alguns meses, o que é muito comum nas regiões tropicais.

O conhecimento da formação e da evolução histórica do espaço urbano, sua implantação, parcelamento e ocupação, oferecem ao pesquisador, uma visão dinâmica da realidade, pois permitirá, através dos anos, compreenderem como o espaço urbano atingiu o seu estado atual e as mudanças que a sociedade vem promovendo.

Os condicionantes naturais podem, juntamente com o manejo inadequado, acelerar a degradação. Chuvas concentradas, encostas desprotegidas de vegetação, contato solorocha abrupto, descontinuidades litológicas e pedológicas, declividade das encostas são algumas das condições que podem acelerar os processos erosivos (Cunha e Guerra, 2006).

A compreensão destes movimentos é fundamental, uma vez que sem o conhecimento da forma e extensão, bem como das causas dos deslizamentos, nunca se chegará a uma medida preventiva, ou mesmo corretiva, que implique na maior segurança (Fernandes e Amaral, 2006).

Especificamente no caso de Petrópolis, a desestabilização das encostas, feita pela construção de casas populares e condomínios, tem provocado o desencadeamento de uma série de problemas ambientais, principalmente quando não existe uma legislação urbanística em sintonia com as limitações físicas, ou quando, apesar de sua existência, ela não consegue ser colocada em prática de forma eficaz, como é o caso da área urbana, estabelecida no $1^{\circ} \mathrm{e}$ $2^{\circ}$ distritos de Petrópolis.

Para se entender os múltiplos aspectos da ocupação e parcelamento do solo em Petrópolis ( $1^{\circ}$ distrito) são necessários considerar aspectos históricos, e principalmente a complexidade do meio físico, como determinantes desse processo.

O processo de ocupação de Petrópolis pode ser dividido em quatro períodos: de 1845 até 1945; de 1945 até 1964; de 1964 até 1976 , e a partir de 1976.

O parcelamento inicial dividia a cidade em lotes denominados prazos de terra, que partindo das ligações viárias, subiam pelas encostas dos morros (Figura 2). O limite desses lotes era fixado pelos divisores de água. A característica principal desses lotes era, portanto, a sua grande profundidade. 


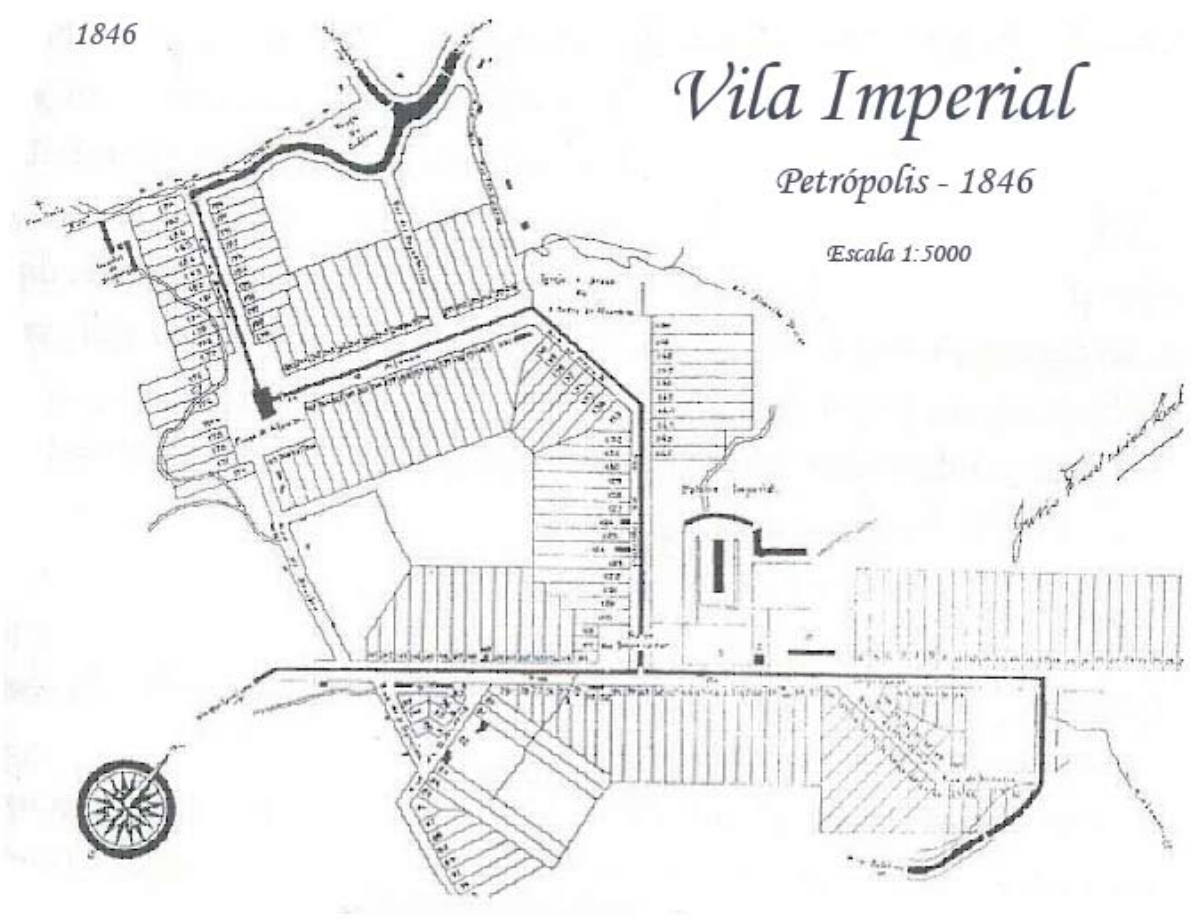

Figura 2 - Planta de Petrópolis e seus quarteirões, realizada por Júlio Frederico Koeler (1861). Fonte: Instituto Histórico e Geográfico de Petrópolis.

Porém, a ocupação urbana até 1945 restringia-se ao fundo dos vales e planícies fluviais, devido à menor densidade urbana e pela legislação vigente na época (Gonçalves, 1998).

Entre 1945 e 1964, com a grande expansão urbana da cidade e as mudanças nas leis de ocupação do município, ocorre o parcelamento indiscriminado dos lotes no sentido de sua profundidade, com a ocupação de encostas adjacentes às áreas já urbanizadas, além de encostas com menor declividade, como os terrenos extremamente perigosos, as faixas de sopé de encostas íngremes e rochosas (IPT, 1991).

Ainda segundo Gonçalves (1998), de 1964 até 1976, a expansão urbana ocorreu sobre setores de encosta cada vez mais problemáticos, onde se conjugam as dificuldades impostas pela alta declividade dos terrenos, a sua instabilidade e as formas inadequadas de parcelamento e edificação. Entretanto, ainda preservam-se setores da encosta mais problemáticos, como trechos de alta declividade (maior do que 75\%) e os terrenos ao longo das linhas de drenagem naturais intermitentes e mesmo perenes, localizados dentro ou junto à malha urbana, não só pelas características topográficas menos favoráveis (maior declividade), como pela preservação da cobertura vegetal próxima da área urbana consolidada.

A partir de 1976, com destaque para segunda metade da década de 80 até os dias atuais, além da abertura de loteamentos executados sem qualquer critério quanto às limitações dos terrenos, a expansão urbana passa a se dar também através de invasões em áreas públicas ou em terrenos não ocupados (Figura 3), até por apresentarem maior declividade e/ou se constituírem áreas sob legislação da APA de Petrópolis, convertendo-se em áreas de risco, situadas no sítio urbano (Gonçalves, 1998; Guerra et al, 2007).

Quanto à Cascatinha ( $2^{\circ}$ distrito), existe uma clara tendência de expansão desordenada, com a ocupação cada vez maior de encostas e os topos de morros, reforçada pela conurbação com o distrito-sede Petrópolis.

Os loteamentos irregulares, aqui estabelecidos, transformaram-se em áreas de risco.

A maior parte desse distrito não possui legislação urbanística e os pedidos de licenciamento de uso, ocupação e parcelamento do solo são analisados por similaridade à legislação vigente, particularmente o Decreto 90/81, que tem vigência apenas na área central de Cascatinha (Gonçalves, 1998).

Essa ocupação irregular é uma das variáveis responsáveis pelo aumento gradual dos movimentos de massa que ocorrem no $1^{\circ}$ e $2^{\circ}$ distritos, que aliada ao desmatamento e assoreamento dos rios principais, coloca em sério risco a população de Petrópolis.

\section{Histórico do planejamento urbano}

O município de Petrópolis começou a ser ocupado por volta de 1720, quando Bernardo Soares de Proença abriu uma 
variante do caminho Rio-Minas, subindo e descendo a Serra da Estrela. Com isso, ele obteve a sesmaria do Itamarati, de onde surgiram várias fazendas, entre elas a do Córrego Seco (atual região da bacia do rio Palatinado), que posteriormente seria adquirida por D. Pedro I. Mas foi somente em 1843 quando D. Pedro II inicia a construção de seu palácio de verão, sob a orientação do major e engenheiro Júlio Frederico Koeler que se dá a colonização de Petrópolis (Rabaço, 1985).

Além dessa tarefa, o major Koeler, profundo conhecedor das características ambientais da região, foi solicitado pelo governo imperial para elaborar um plano urbanístico, que por muito tempo direcionaria a ocupação no município de Petrópolis (Figura 2). O planejamento da ocupação foi feito seguindo o curso dos três principais rios da cidade: Palatinado, Quitandinha e Piabanha.

O plano visava à preservação das matas e o aproveitamento do solo para seu cultivo, estabelecendo-se assim,

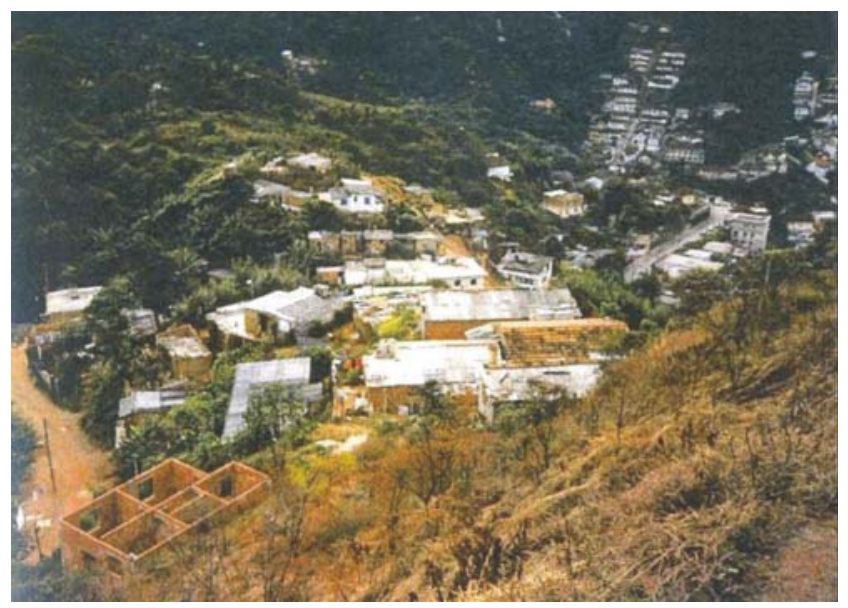

Figura 3 - Área de invasão junto ao Centro Histórico de Petrópolis Morro do Teleférico ( $1^{\circ}$ distrito). Foto: Luiz F. H. Gonçalves

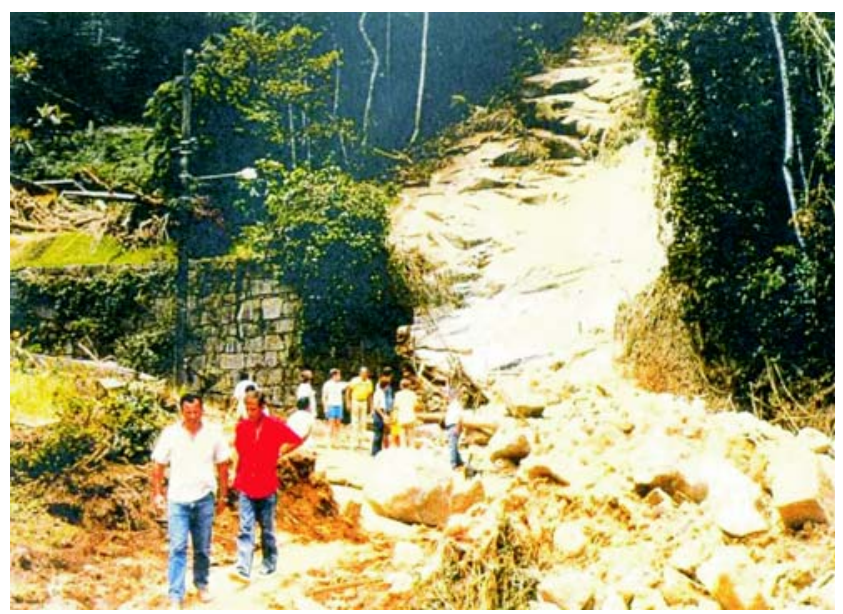

Figura 5 - Escorregamento com queda de blocos no bairro Morin (1 ${ }^{\circ}$ distrito). Foto: L. F. H. Gonçalves, 1998. uma colônia agrícola, que tiraria proveito do grande manancial de água representado pelos inúmeros rios.

O planejamento idealizado por Koeler foi o primeiro código de obras petropolitano (Rabaço, 1985). As principais disposições do regulamento urbanístico elaborado por Koeler possuíam uma orientação para o aproveitamento, adaptação e preservação das áreas urbanas, como:

- Os lotes seguiam-se ao longo dos rios e tinham mais profundidade que largura (55m x 110m), subindo pelas encostas dos morros, adaptando-se à topografia acidentada;

- Era proibido utilizar o topo dos morros; proibido também a subdivisão dos lotes; as áreas com maior declividade não poderiam ser ocupadas, preservando-se a sua cobertura vegetal para evitar deslizamentos;

- Os proprietários tinham que plantar árvores nativas na testada dos terrenos; realizar a construção de calçada com

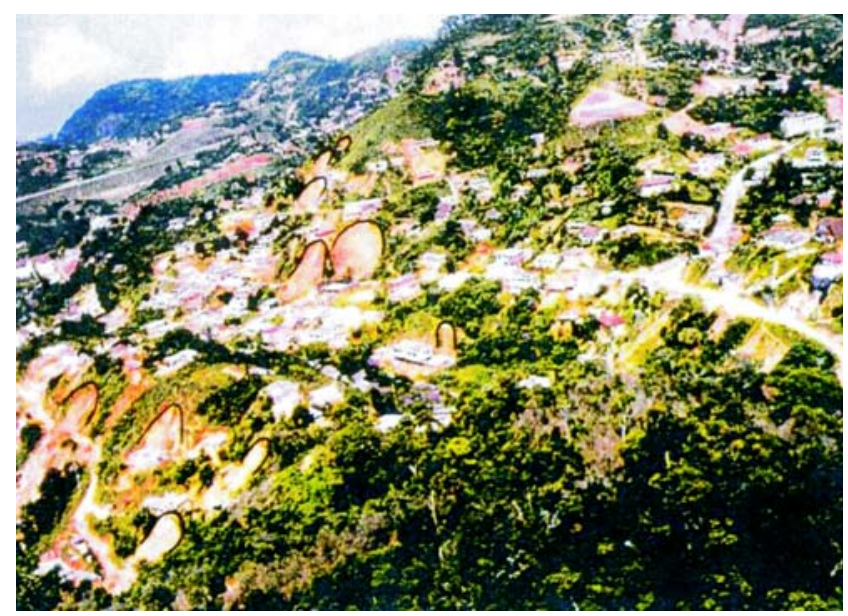

Figura 4 - Escorregamentos generalizados no bairro Vila Felipe $\left(1^{\circ}\right.$ distrito). Fonte: IPT, 1991.

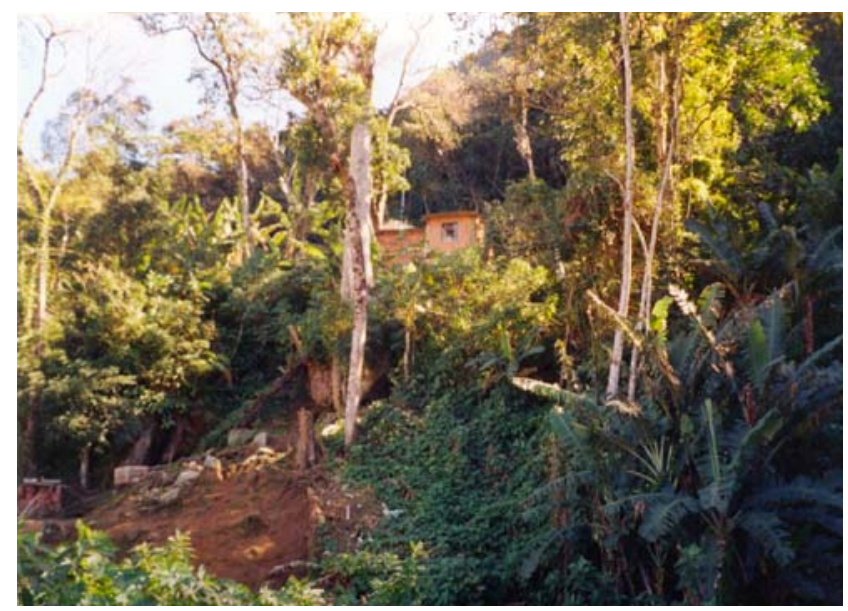

Figura 6 - Corrida de lama próximo às casas construídas em área de risco. Vila São Francisco, Petrópolis, 2003. 
2,20 m de largura em alvenaria no prazo de um ano e em pedra no prazo de oito anos;

- Obrigação de cercar ou murar solidamente os prazos (lotes) de terra, dentro de um ano no máximo;

- Prévia aprovação das fachadas dos prédios;

- Obrigação de construir dentro de dois a quatro anos;

- Aos proprietários exigia-se que fosse conduzida a água dos telhados para as ruas por meio de canos;

- Todas as residências fariam frente para os rios, sendo que os esgotos seriam lançados em fossas no fundo dos terrenos, distantes dos cursos d’água, evitando-se assim qualquer tipo de contaminação dos mesmos.

A planta urbanística elaborada por Koeler para Petrópolis teve a originalidade de modificar o velho estilo colonial de construir as casas de fundos para os rios que eram utilizados com a simples função de esgoto. Koeler, revolucionando esse costume, aproveitou os cursos de água de que é rica a região petropolitana, banhada pelo rio Piabanha e seus inúmeros afluentes, para traçar ao longo de suas margens, as avenidas da Vila Imperial e as ruas de acesso aos bairros circundantes (Rabaço, 1985).

Com o passar do tempo a atividade agrícola entra em crise por muitos fatores. O clima mais frio da área serrana, as características do solo e a propensão à erosão limitaram a atividade agrícola, sem contar o relevo acidentado. Atribuíase também o malogro, ao pequeno tamanho dos lotes (55m x $110 \mathrm{~m}$ ) considerados impróprios para a rentabilidade agrícola (Magalhães, 1966).

\section{A ocupação do solo e sua relação com a incidência de movimentos de massa}

Para o entendimento dos múltiplos aspectos do parcelamento e da ocupação do solo de Petrópolis, é necessário levar em consideração a condição de cidade serrana, e as conseqüentes limitações naturais para a sua ocupação. O processo de subdivisão mais comum dos lotes consiste na abertura de uma via que sobe toda a encosta, para qual se voltam às frentes dos novos lotes criados.

Muitas vezes, a via local transforma-se, em seus pontos mais altos, em escadas, para que se aproveite ao máximo o terreno em toda a sua profundidade. Essa forma de ocupação do solo, característica do município, destaca-se como a mais comum de expansão da área urbana, responsável por desmatamentos e movimentos de massa (Figura 4).

A realização de um estudo espaço-temporal dos movimentos de massa é de fundamental importância para avaliar a intensidade da ação antrópica, combinada com os condicionantes físicos, ao longo das últimas décadas.

As informações utilizadas para a identificação temporal dos deslizamentos foram retiradas do Banco de Dados sobre Escorregamentos em Petrópolis (IPT, 1991a), referindose ao período de 1960 até 1989.

Os dados do período de 1990 até os dias de hoje foram obtidos através de pesquisa nos arquivos dos jornais Tribuna de Petrópolis e Diário de Petrópolis, além de terem sido conferidos e corrigidos os dados do IPT (1991b) e da Defesa Civil. A necessidade de atualização visa dar continuidade aos estudos sobre deslizamentos em Petrópolis, que se acentuam à medida que ocorre a expansão urbana.

As informações foram coletadas utilizando-se de um boletim próprio para descrição dos movimentos de massa. Além de localizar os eventos, foi classificado quanto ao tipo de ocorrência e material, o índice pluviométrico do dia, como o prejuízo material e o número de óbitos.

Seguindo uma tendência nacional, o crescimento da população urbana supera a rural no município, dando início à expansão da malha urbana para além dos limites estabelecidos por Koeler (Rabaço, 1985), acelerando o desmatamento através de uma ocupação e parcelamento sem critérios das rampas adjacentes às áreas urbanizadas, que resultaram em invasões e loteamentos irregulares desprovidos de saneamento básico, onde se estabelece uma população de baixo poder aquisitivo.

O Código de Obras de 1960 também não demonstra qualquer preocupação com a preservação florestal, abrindo precedentes para que interesses especulativos viessem a ocupar as áreas ociosas que apresentavam elevada valorização junto ao $1^{\circ}$ distrito, além de permitir a criação de loteamentos o que até então era vetado pelo Plano Koeler. Além disso, o poder público municipal foi incapaz de controlar e fiscalizar a abertura de loteamentos, ou delimitar áreas para este tipo de ocupação.

Nesta década, aliado ao início do processo de ocupação desordenada da área urbana, os elevados índices pluviométricos, principalmente em 1966, contribuíram para a ocorrência de movimentos de massa, com destaque para os escorregamentos. Assim, ao avaliarmos a incidência dos movimentos de massa na década de 60 , temos o prenúncio das conseqüências futuras que a expansão urbana poderá causar.

Os movimentos, ao serem avaliados por década, confirmam a maior ocorrência no $1^{\circ}$ distrito, decrescendo até o $5^{\circ}$ distrito (Posse). Esse declínio pode ser explicado quando consideramos duas variáveis: a diminuição dos índices pluviométricos para o interior do município, como pelo menor processo de urbanização nos distritos, que seguem em direção ao vale do Paraíba.

Nas quatro décadas avaliadas, houve um predomínio quase absoluto dos escorregamentos, dentre os outros movimentos de massa que foram considerados, como a corrida de lama e a queda de blocos (Figuras 5 e 6). 


\section{Considerações Finais}

A avaliação integrada entre os mapas de movimentos de massa por década, com o de caracterização do relevo demonstra que a incidência de movimentos de massa apresenta uma correspondência direta com a ocupação, pluviosidade e o relevo, variando de acordo com cada década avaliada.

Os movimentos ocorridos na década de 60 estavam mais relacionados aos índices pluviométricos em si, do que à ocupação desordenada que ainda era restrita. As áreas atingidas por movimentos de massa ocorriam geralmente em diversos pontos da área urbana, não havendo uma correlação direta com algum tipo de ocupação ou feição do relevo específico.

A década de 70 apresentou um aumento do número de movimentos de massa, apesar dos totais pluviométricos terem sofrido uma redução. Nesta década de grande crescimento populacional e leis ambientais politicamente flexíveis e omissas, a ocupação sobrepujou a precipitação, assumindo a maior responsabilidade pela ocorrência de movimentos de massa, pois as novas áreas que foram incorporadas de forma inadequada à malha urbana, apresentavam limitações físicas à ocupação.

Já a década de 80, teve um expressivo número de movimentos de massa, sendo maior que os da década de 60 e 70 , entretanto, os totais pluviométricos não acompanharam os valores da década anterior, mostrando-se mais elevados.

Vale ressaltar a década de 80 como uma década de diagnóstico, pois se observa que a ocupação desordenada sobre áreas de relevo mais acidentado, aliado aos maiores totais pluviométricos, facilitou a ocorrência de movimentos de massa, como não haviam ocorrido até então na história do município.

O período compreendido entre 1980 e 1989 foi marcado pelo empobrecimento geral da população. Essa década é o resultado do enfraquecimento da legislação ambiental iniciada na década de 60 , e da ocupação desordenada na década de 70, o que permitiu a rápida ocupação das áreas de relevo acidentado, que por apresentarem menor valorização, foram ocupadas pela população de baixa renda, atendendo aos interesses especulativos e políticos locais.

Sendo assim, com o aumento dos totais pluviométricos na década de 80, os movimentos de massa também se intensificam, expondo as conseqüências da ação antrópica na área urbana, através dos movimentos de massa que tornaram o município conhecido internacionalmente, durante a grande enchente de fevereiro de 1988.

Dentre as décadas avaliadas, a década de 90 apresentou o menor número de eventos catastróficos. Foi caracterizada pelas inúmeras invasões e ocupações informais em quase todos os distritos, onde o poder público não tomou qualquer atitude direta para reverter essa situação. Essa omissão não impediu que novas áreas de risco se formassem, o que favoreceu (e ainda favorece) os movimentos de massa no futuro.

Torna-se importante mencionar a variável ocupação como a responsável direta pelos movimentos de massa na área urbana, tornando-a mais vulnerável a eventos catastróficos, mesmo com chuvas de pouca intensidade e volume, como aconteceu nos anos analisados da década de 90. Dessa forma, apesar das limitações impostas pelas características físicas, a ocupação tornou-se a variável mais expressiva para a fragilização da área urbana aos eventos catastróficos nos últimos 40 anos, no município, que voltou a sofrer uma catástrofe séria em 2001, quando morreram 50 pessoas, devido aos totais pluviométricos elevados, associados à ocupação desordenada, em especial no $1^{\circ} \mathrm{e} 2^{\circ}$ distritos.

O grande desafio está em compatibilizar a expansão da área urbana às características físicas do município. $\mathrm{Na}$ área de estudo existem graves limitações físicas a novas ocupações, devido ao predomínio do relevo montanhoso, com presença de serras escarpadas, morros alongados, paredões e uma série de fraturas e falhamentos, sendo imprescindível impedir novas ocupações sejam informais ou não, garantindo a preservação da vegetação nativa, que envolve a área urbana e está presente no seu interior.

Quanto à presença dos loteamentos irregulares e invasões que já foram incorporadas à área urbana, é necessário que o poder público impeça que continuem a crescer desordenadamente, realizando obras de saneamento básico que garantam segurança à população residente, como incentivo ao reflorestamento. Para algumas comunidades, no entanto, em função dos riscos que estão submetidas, por sua localização, precisam ser removidas para locais mais seguros.

Para que tais medidas obtenham resultado, faz-se necessário a integração entre os poderes públicos no município, no sentido de preservar a cobertura vegetal, orientar e fiscalizar a ocupação, e assegurar e manter a qualidade de vida da população residente no mesmo, com destaque para os distritos de Petrópolis e Cascatinha, onde a ação antrópica está em desarmonia com o meio ambiente. Os eventos catastróficos ocorridos nesses dois distritos devem servir de exemplo para os outros três distritos, em especial Itaipava, que vem passando por um processo de urbanização acelerado desde a década de 90, principalmente através dos condomínios e loteamentos.

\section{Referências Bibliográficas}

Almeida, M.C.J.; Nakazawa, V.A. \& Tatizana, C. (1991) Levantamento e cadastro dos escorregamentos no município de Petrópolis, RJ. In: Simpósio de 
Geografia Física Aplicada, 4., Porto Alegre. Anais... Porto Alegre: UFGRS. p. 292 - 299.

Brasil. Ministério das Minas e Energia. Projeto Radambrasil. (1983) Levantamento de recursos naturais. v. 32. Rio de Janeiro: Projeto Radambrasil.

Centro de Informações de Dados do Rio de Janeiro - CIDE. (1983) Anuário Estatístico do Estado do Rio de Janeiro. Rio de Janeiro. 583p.

Christofoletti, A. (1994) Aplicabilidade do conhecimento geomorfológico nos projetos de planejamento. In: Guerra, A .J.T.\& Cunha, S.B. (Orgs.). Geomorfologia: uma atualização de bases $e$ conceitos. 1. ed. Rio de Janeiro: Editora Bertrand Brasil. p. 415-440.

Cunha, S.B \& Guerra, A.J.T. (2006) Degradação Ambiental. In: Guerra, A.J.T. \& Cunha, S.B. (Orgs.). Geomorfologia e Meio Ambiente. 6. ed. Rio de Janeiro: Editora Bertrand Brasil. p. 337-379.

Departamento de Recursos Minerais - DRM. (1981) Projeto carta geológica do Estado do Rio de Janeiro, folha de Itaipava, relatório final. Niterói: DRM.

Ellemberg, H. \& Mueler-Dombois, D. (1965/66) Tentative physiognomic ecological classification of plant formation of the earth. Bericht Uber des Geobotanische Institut. Rubel, Zurich, 37: 21-25.

Fernandes, N. F \& Amaral, C.P. (2006) Movimentos de Massa: uma abordagem geológico-geomorfológica. In: Guerra, A.J.T. \& Cunha, S.B. (Orgs.). Geomorfologia e Meio Ambiente. Rio de Janeiro: Editora Bertrand Brasil. 6. ed. p. 123-194.

Fundação Instituto Brasileiro de Desenvolvimento Econômico e Social do Rio de Janiero - FIDERJ. (1978) Indicadores Climatológicos do estado do Rio de Janeiro. Rio de Janeiro. (Série SIPE - Sistema de Informações para o Planejamento Estadual). 156 p.

Gonçalves, L.F.H. \& Guerra, A.J.T. (2006) Movimentos de Massa na Cidade de Petrópolis (Rio de Janeiro). In: Guerra, A.J.T. \& Cunha, S.B. (Orgs.). Impactos Ambientais Urbanos no Brasil. 4. ed. Rio de Janeiro: Editora Bertrand Brasil. p. 189-252.

Gonçalves, L.F.H. (1998) Avaliação e diagnóstico da distribuição espacial e temporal dos movimentos de massa com a expansão da área urbana em Petrópolis - RJ. 170 f. Dissertação (Mestrado em Geografia). Departamento de Geografia, UFRJ, Rio de Janeiro.

Guerra, A.J.T. (1995) Catastrophic events in Petrópolis City (Rio de Janeiro State), between 1940 and 1990. GeoJournal, 37 (3): 349-354.

Guerra, A.J.T. \& Favis-Mortlock, D. (1998) Land degradation in Brazil. Geography Review, 12 (2): 18-23.

Guerra, A.J.T. (2007) Processos Erosivos nas Encostas. In: Guerra, A.J.T. \& Cunha, S.B. (Orgs.). Geomorfologia: uma atualização de bases $e$ conceitos. 7. ed. Rio de Janeiro: Editora Bertrand Brasil. p. 149-209.

Guerra, A.J.T.; Oliveira, A.; Oliveira, F. \& Gonçalves, L.F.G. (2007) Mass Movements in Petrópolis, Brazil. Geography Review, 20 (4): 34-37.

Instituto Brasileiro de Geografia e Estatística - IBGE (2004) Anuário Estatístico. Instituto Brasileiro de Geografia e Estatística.

Instituto de Pesquisas Tecnológicas - IPT (1991a) Carta Geotécnica de Petrópolis - RJ. volumes 1 e 2.

Instituto de Pesquisas Tecnológicas - IPT (1991b) Banco de Dados sobre movimentos catastróficos de Petrópolis, entre 1940 e 1990. São Paulo: IPT.

Magalhães, J.C. (1966) A função industrial de Petrópolis. Revista Brasileira de Geografia - IBGE, 1: 19-55.

Nimer, E. (1989) Climatologia do Brasil. 2. ed. Rio de Janeiro: IBGE - Departamento de Recursos Naturais e Estudos Ambientais. 421p.

Penha, H.M.; Ferrari, A.L.; Junho, M.C.B.; Souza, S.L.A. de \& Brenner, T.L. (1981). Projeto Carta Geológica do Estado do Rio de Janeiro. Folha Itaipava. Relatório final. Rio de Janeiro: Convênio DRM/ IG-UFRJ.

Rabaço, H.J. (1985). História de Petrópolis. Petrópolis: Instituto Histórico de Petrópolis. 140p.

United Nations Educational, Scientific and Cultural Organization - UNESCO. (1973) International Cartography and Classification of Vegetation. Ecology and Conservation 6. Paris: UNESCO. 93p 